\title{
Behaviour of Axially Restrained Steel Columns During Fire
}

\author{
FARIS A. ALI, IAN W. SIMMS and DAVID J. O'CONNOR \\ School of the Built Environment \\ University of Ulster \\ Jordanstown, Co. Antrim, BT37 OQB, Northern Ireland, UK
}

\begin{abstract}
Imposing axial restraint against column thermal expansion during fire causes additional axial forces to be generated and develops excessive buckling deformations. Hence, an early failure can take place which may lead to partial failure of the building during fire. This paper discusses an extensive experimental study which is being undertaken to investigate the axial restraint effect on column performance under high temperatures. The paper details the experimental programme, and the factors included in the parametric study. A loading rig was specially designed to permit the application of axial load together with the imposition of axial restraint. As a part of the main experimental programme a pilot study was performed to identify factors that might affect the experiment environment and to modify the envisaged test methodology of the main programme. The pilot study involved testing ten steel columns of one section, slenderness $\lambda=152$, under temperatures up to $1000^{\circ} \mathrm{C}$, where three levels of axial restraint and loads were involved.
\end{abstract}

KEYWORDS: Steel, Column, Axial Restraint, High Temperatures, Fire.

\section{INTRODUCTION}

During the last decade fire engineering design has developed significantly, and the performance of steel columns in fire hazardous conditions is one of the important fields of theoretical and experimental study. Previously, various methods have been developed to analyse and predict the actual performance of steel columns in fire situations[1,2,3,4,5,6]. Some of those methods have used analytical techniques but their progress has been slow [7]. Franssen et. al. [5] from Liege University have investigated this subject and a design method has been developed and proposed as an alternative to the current proposals of Eurocode3 Part 1.2 [8]. This method was assessed by Bailey, Newman et. al. [9] in a recent report of the Steel Construction Institute, UK, which 
sought to calibrate and simplify the design rules for steel columns in fire to Eurocode [8]. Olawale et. al. [6] , Burgess et al. [3], Newman et. al. [9] have investigated this question and also the effect of imperfections, including initial straightness and residual stresses, in an attempt to obtain more calculation accuracy. Investigations generally have used numerical modelling supported by computer programs and several fire structural analysis packages have been developed, including FIRES; University of California, CEFICOSS; University of Liege, LUSAS; Imperial College, London, INSTAF; University of Sheffield and others [7].

This extensive theoretical research has been in need of a wide database of test results to verify the accuracy of computational models and to provide information necessary to understand the actual behaviour of steel columns during fire. Indeed, they have in some part been able to use results from many tests, executed in the past in the UK, Germany, Netherlands, France, Belgium and other countries [1,11,12]. A valuable database of steel columns tested under high temperatures has been collated by Franssen [11] which contains significant details of column fire tests performed in Europe during the last many years. Most of these tests were of columns, which were free to expand during heating, although some tests were carried out with near full restraint (which case cannot be found in practice) and no intermediate degrees of restraint were investigated. There is an obvious need for a co-ordinated test programme, providing an integrated parametric experimental study, where the influence of such factors as loading level and restraint degree are investigated together with their interactions, to provide a full package of test data, permitting a factors interaction analysis to be carried out. In addition, it is advisable to have clear documentation of initial test conditions, like imperfection factors [13] including initial straightness and the degree of friction within the assumed pinned end supports, affecting the test effective length.

The objective of this paper is to represent an experimental study on the behaviour of steel columns under high temperatures. The research focuses on the effect of axial restraint on the fire resistance of steel columns. The paper discusses the restraint degrees and the load levels examined in the test program. The test methodology is detailed and the test rig and furnace and the instrumentation is described. Finally, the test results, gathered within a pilot study executed as a part of the experimental program, are presented.

\section{THERMAL EXPANSION AND AXIAL RESTRAINT}

Under high temperatures a column thermal expansion can take place. If the axial expansion is restrained axial force will be generated in the column. The value of the force $\mathrm{P}_{\mathrm{r}}$ is dependent on the stiffness of the surrounding building parts that contribute to restraining the column expansion during fire. If the stiffness of those elements is replaced with a spring of stiffness $\mathrm{K}_{\mathrm{s}}$

(Figure 1) then the value of $\mathrm{P}_{\mathrm{r}}$ can be calculated using basics of structural mechanics:

$\mathrm{P}_{\mathrm{r}}=\Delta_{\text {TOTAL }} \cdot \mathrm{K}_{\mathrm{S}}$

where $\Delta_{\text {TотAL }}-$ is the total change in the column length during heating: 
$\Delta_{\text {TOTAL }}=\Delta_{\text {THERM }}-\Delta_{\text {DET }}-\Delta_{\text {REST }}$

The first term on the RHS of equation (2) represents the free thermal expansion of the column:

$\Delta_{\text {THERM }}=\alpha \Delta \mathrm{TL}$

where $\Delta T=$ temperature difference, $L=$ column length and $\alpha=$ coefficient of thermal expansion. The second term in equation (2) is the shortening in the column length under the effect of the applied loads attenuated by material property deterioration at elevated temperatures:

$\Delta_{\mathrm{DET}}=\frac{\mathrm{PL}}{\mathrm{AE}_{\mathrm{T}}}-\frac{\mathrm{PL}}{\mathrm{AE}}$

where $\mathrm{P}$ - is the applied load, $\mathrm{A}$ - is the column cross section area, $\mathrm{E}_{\mathrm{T}}, \mathrm{E}$ are the values of Young modulus at temperature $T$ and at ambient temperature respectively. The last term in equation (2) is the shortening caused by the axial restraint forces $P_{r}$ generated at temperature T:

$$
\Delta_{\text {REST }}=\frac{\mathrm{P}_{\mathrm{r}} \mathrm{L}}{\mathrm{AE}_{\mathrm{T}}}
$$

It is useful to consider restraint stiffness in relative terms by the factor $\alpha_{K}$, defined as the relation between the equivalent stiffness of the restraining elements $K_{S}$ and the axial stiffness of the expanding column:

$$
\alpha_{\mathrm{K}}=\frac{\mathrm{K}_{\mathrm{S}}}{\mathrm{K}_{\mathrm{c}}(\mathrm{T})}
$$

By substituting equations (3), (4) and (5) into equation (2) and then substituting the obtained $\Delta_{\text {TотAL }}$ in equation (1) (taking into consideration equation (6) and performing some simplifications) an equation for calculating the axial force generated in an axially restrained column subjected to high temperatures can be obtained as follows:

$$
\mathrm{P}_{\mathrm{r}}=\alpha_{\mathrm{K}} \mathrm{K}_{\mathrm{c}}(\mathrm{T}) \mathrm{L} \cdot f_{1} \cdot f_{2}
$$

where:

$$
\begin{aligned}
& f_{1}=\alpha \Delta \mathrm{T}-\frac{\mathrm{P}}{\mathrm{A}}\left(\frac{\mathrm{E}-\mathrm{E}_{\mathrm{T}}}{\mathrm{E} \cdot \mathrm{E}_{\mathrm{T}}}\right), \\
& f_{2}=\frac{\mathrm{AE}_{\mathrm{T}}}{\mathrm{AE}_{\mathrm{T}}+\alpha_{\mathrm{K}} \mathrm{K}_{\mathrm{c}}(\mathrm{T}) \mathrm{L}}
\end{aligned}
$$


Apart from material properties and geometrical factors, it is obvious from equation (7) that the values of $P_{r}$ can be significantly influenced by the degree of restraint $\alpha_{K}$, and the level of the applied loads denoted by the load ratio $\left(\alpha_{\mathrm{L}}\right)$ :

$\alpha_{L}=\frac{P}{P_{c y}}$

where $P_{c y}$ - is the column load capacity. This factor $\alpha_{L}$ can significantly interact with the restraint parameter $\alpha_{\mathrm{K}}$ and increases the probability of premature column failure during fire. In addition, the magnitude of forces generated in a column during fire is influenced by the temperature difference between the column and the restraining elements [2]. When a fire takes place in a compartment the other parts of the building remain relatively cool. This increases the influence of the restraint in enhancing the buckling loads.

It is important to emphasize that the column stiffness $\mathrm{K}_{\mathrm{c}}$ in equation (7) is dependent on temperature value. Therefore, the reduction in the stiffness value during column heating can significantly affect the value and rate of the generated axial forces.

\section{THE TEST PROGRAMME}

An extensive experimental program has been designed and is being executed at the Fire Research Centre, of University of Ulster. The objective of this programme is to study the effect of axial restraint on the fire resistance of steel columns and includes a major study, comprising 45 fire tests and a pilot study of some 10 fire tests, which have been used to commission the test methodology. The influence of two principal factors are being investigated, the degree of axial restraint $\alpha_{K}$, and the loading level $\alpha_{L}$, as described above. Special care has been taken to direct the parametric study towards factor levels that can be found in practice. To this end, two previously recorded load tests on real buildings were referenced. The first, was a study performed by T. Lennon [14] from the Building Research Establishment prior to real fire tests carried out at the large building test facility in Cardington, UK. The research revealed a range of degrees of restraint $\alpha_{\mathrm{K}}$ between 0.05 and 0.35 depending on the column position in the building. The second, was the a Broadgate Fire Report [10], which took place in 1990. That report concluded with a range of restraint degrees $\alpha_{K}$ between 0.01 and 0.9 , although it should be stressed that all the measured values of $\alpha_{K}$ were between $0.1-0.35$ except what seems like a single rogue value of $\alpha_{\mathrm{K}}=0.9$.

The full extent of the main experimental programme is illustrated in Figure 2. Three column sections have been chosen. Column heights are essentially half scale at $1.8 \mathrm{~m}$, and sections sizes were chosen so as to give a range of slenderness ratios about the weak axis, representative of typical situations in practice, namely $\lambda=49,75$ and 98 . In accordance with discussion above, values of $\alpha_{\mathrm{K}}$ were taken as $0.1,0.35$ and 0.6 to insure a reasonable cover of the measured values referenced. 


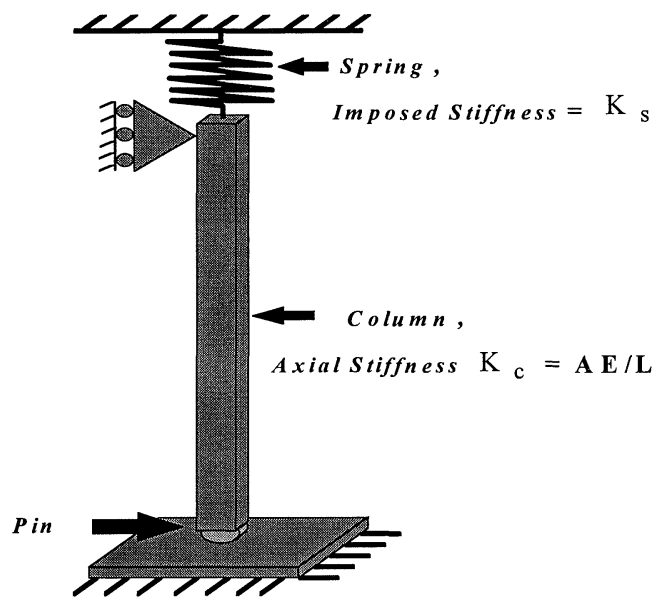

FIGURE 1. Definition of imposed axial restraint.

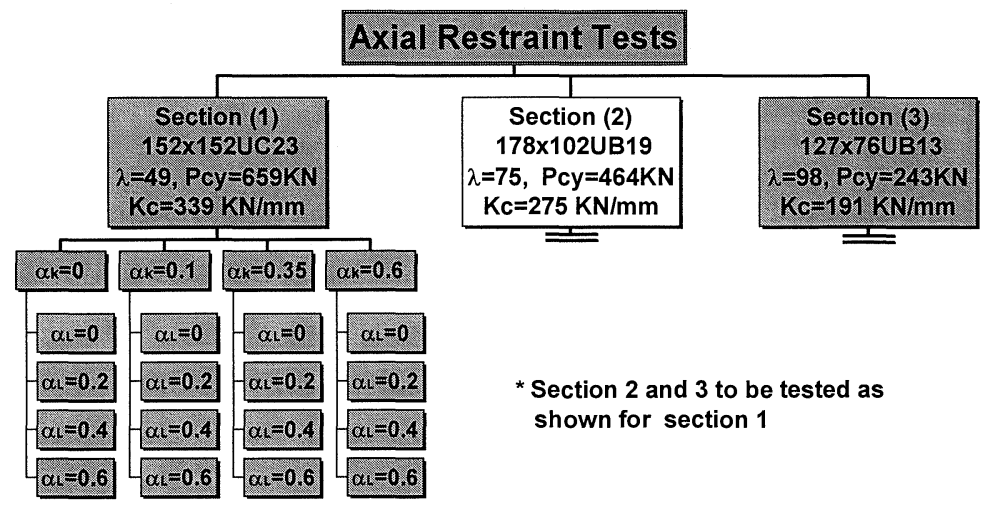

FIGURE 2. Presentation of the experimental program.

The loading levels $\alpha_{\mathrm{L}}$ involved in the experimental program were determined assuming that a load safety factor is usually taken between 1.6 -1.8 in engineering design. This gives a maximum loading level $\alpha_{L}=0.6$ that may be encountered in practice. Therefore, values of $\alpha_{L}=0,0.2,0.4$ and 0.6 levels were included in the test programme. 


\section{Test Rig}

Figure 3 shows a three dimensional representation of the rig which has been designed to execute the test programme described previously. The rig had the capability of applying:

1. Axial loads only. This can be achieved by applying load to the column via the lateral beam (1) shown in Figure 3. By Loosening the restraining nuts (4) the beam is free to move vertically and the columns thermal expansion is therefore unrestrained.

2. Axial restraint only. In this case the lateral beam (1) is used to restrain the columns thermal expansion. The ends of the beam are therefore restrained by flexible supports consisting of the springs (5) held in position on the threaded bars using the restraint nuts (4) as shown in Figure 3.

3. Loads and restraint at the same time. This can be done by imposing loads on the column via the lateral beam (1) and simultaneously applying restraint as described in 2 above.

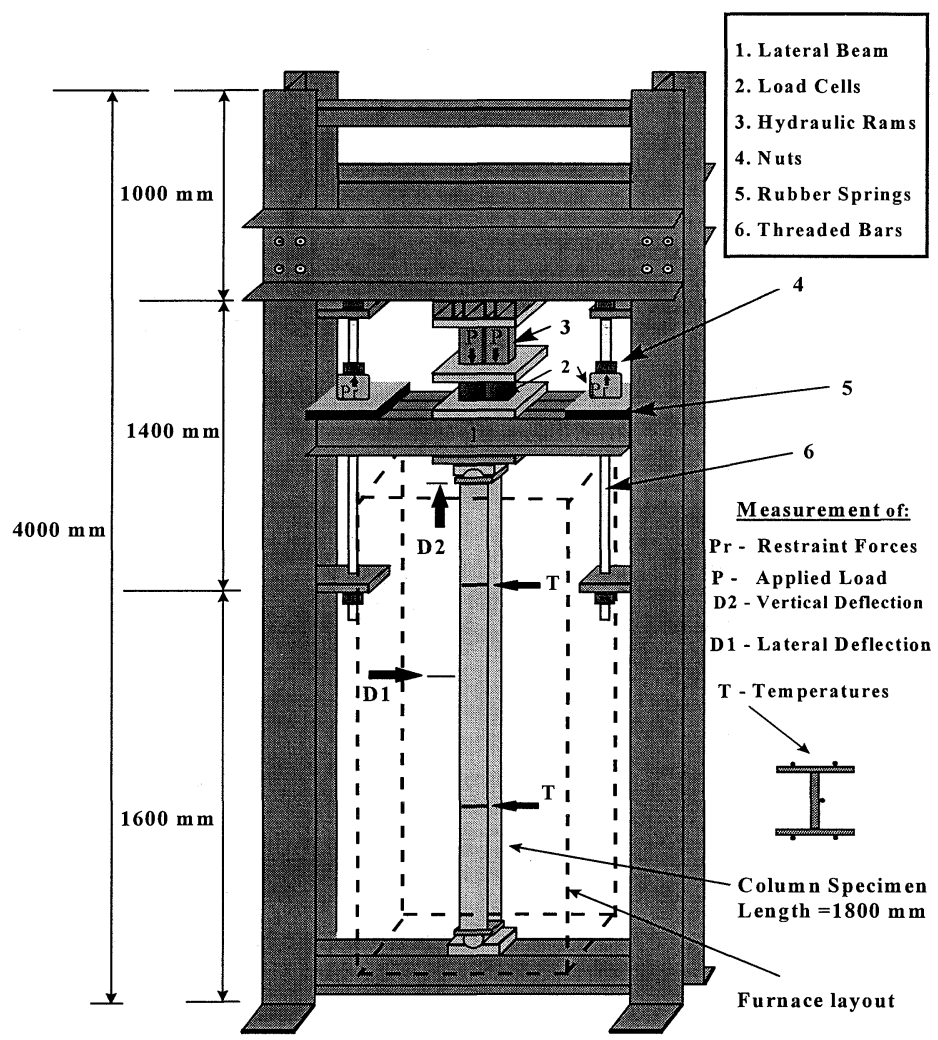

FIGURE 3. Axial restraint test rig. 


\section{Instrumentation}

Steel temperatures were recorded using thermocouples located at the two quarter span positions at five points across the section. In addition, the applied loads, restraint forces, axial and lateral deflections were also measured. Loads were recorded using four load cells, two for the applied loads and two for the restraint forces as shown in Figure 3. Lateral deflections were measured at mid height on either side of the columns weak axis. The deflections were measured via quartz rods, attached to the column, by two LVDT's located outside the furnace. Vertical deflections were recorded by a single LVDT attached to the lateral beam (1) and were measured relative to an independent reference frame. A Spectralab data logger was used to record the output test data from all of this instrumentation.

\section{Furnace Description and Test}

A general layout of the furnace is shown in Figure 3. The furnace consists of a steel frame which has been fabricated using light angle sections. This basic frame has then been infilled with insulation material to create the walls, roof and floor of the furnace. The furnace is designed to produce temperatures up to $1000{ }^{\circ} \mathrm{C}$ using Propane gas and allows a constant rate of heating of $10^{\circ} \mathrm{C} / \mathrm{min}$ to be applied.

One of the main criticisms raised in the past about similar tests is the possibility of nonuniform distribution of temperature over the column height which can significantly effect the test environment and results [13]. Therefore, several tests were performed to investigate and improve the temperature distribution in the furnace. Modifications were made continuously which ended with a $20^{\circ} \mathrm{C}$ maximum difference in the temperature along the column height when the average furnace temperature was $800^{\circ} \mathrm{C}$.

\section{TEST METHODOLOGY}

The test specimen was fixed to the bearings at each end using four bolts to prevent any accidental eccentricity. The load was then applied to the column using the two rams through the lateral beam1 (Figure 3). When the required loading level was reached (which was kept constant through the test) the nuts (4) were tightened and the heating process started. During heating, the column tends to expand upwards but it was resisted by the pair of springs (5) and the nuts (4) shown in Figure 3. The heating continued at the rate of $10^{\circ} \mathrm{C} / \mathrm{min}$ until failure took place when the lateral deflection at the middle height of the column reached a runaway situation. During all the mentioned activities the applied load, axial forces generated during heating, temperatures, lateral and vertical deflections were recorded on constant time periods basis.

\section{Imperfections and SmithSouthwell}

It is well known that the buckling capacity of struts is affected by the presence of initial 
curvature and accidental eccentricities of load. The tests in this study are generally 'one offs' in that usually only one specimen will be subjected to each combination of loading effects. As this does not provide statistically significant data on the effects of initial curvature and accidental eccentricity, these parameters must therefore be eliminated or controlled in some way.

A methodology, consisting of two parts has been developed aimed firstly at reporting measured values of initial curvature and secondly controlling the effects of accidental eccentricity. The initial curvatures were recorded by means of a simple system of direct measurement using a displacement transducer and an accurate datum line. Controlling the effect of accidental eccentricity is achieved by means of a Smith Southwell Plot. During each test, the load application is commenced in increments while the lateral deflection associated with each increment is recorded. This provided data which could be used to produce a Smith Southwell plot and by means of a linear regression analysis the initial imperfection in the system can be identified.

\section{THE PILOT STUDY}

At the Fire Research Laboratories, University of Ulster, a pilot study was carried out to develop a perceptive understanding of the test conditions and to identify the parameters that may influence the test environment. Therefore, a group of 1.6 meter length pin ended steel columns made of one light section IPE $80 \times 46$ were tested under ambient and high temperatures up to $1000^{\circ} \mathrm{C}$.

\section{Tests at Ambient Temperatures}

Most experimental work carried out on columns to date has been in the form of standard fire tests. Often the ends rotation restraint occurring in such experimental settings has not been reported and is considered to be a serious omission [13]. It was therefore considered important to establish the degree of rotation restraint provided by the bearing in this test program. This has been achieved by loading a test specimen until it fails at ambient temperature and comparing this failure load to the result from Euler and Perry Roberston equations to assess the value of effective length occurring in the test apparatus. By experimenting with various lubricants in a trial and error approach an effective length 0.99 times the actual column length was obtained. Considering the results summarised in Table 1 it is clear that the experimental failure loads recorded in tests TP101 and TP110 are greater than the values given by the Euler and Perry Robertson equations using an effective length of $1.0 \mathrm{~L}$. This is caused by frictional resistance in the bearings creating a rotational restraint which reduces the effect length of the member. For each of the experimental results the equivalent effective length has been calculated and is reported in Table 1 . This value has then been used in the modified Perry Robertson calculation reported in the Table. These values tend to show slightly better agreement with the experimental results. 
TABLE 1. Ambient temperatures experimental and calculated failure loads of the pilot study.

\begin{tabular}{|l|l|l|l|l|l|l|l|l|}
\hline $\begin{array}{l}\text { Specimens } \\
\text { Reference }\end{array}$ & \multicolumn{5}{|c|}{ Failure loads in KN } & $\begin{array}{l}\text { Initial } \\
\text { Curvature } \\
\text { (mm) }\end{array}$ & $\begin{array}{l}\text { Effective } \\
\text { Length }\end{array}$ \\
\cline { 2 - 9 } & $\begin{array}{l}\text { Test } \\
\text { Results }\end{array}$ & $\begin{array}{l}\text { Smith } \\
\text { Southwell }\end{array}$ & Euler & $\begin{array}{l}\text { Perry } \\
\text { Roberston }\end{array}$ & BS5950 & Modified & & \\
\hline TP101 & 85.25 & 86.69 & 67.09 & N/A & 55.00 & 77.45 & N/A & $0.88 \mathrm{~L}$ \\
\hline TP110 & 80.09 & 84.07 & 67.09 & 64.13 & 55.00 & 79.26 & 0.2 & $0.893 \mathrm{~L}$ \\
\hline TP111 & 67.09 & 67.33 & 67.09 & 65.94 & 55.00 & 65.94 & 0.1 & $0.998 \mathrm{~L}$ \\
\hline
\end{tabular}

\section{High Temperatures Tests}

Seven columns have been tested under high temperatures involving three degrees of restraint $\alpha_{K}=0,0.042$ and 0.32 and three loading levels $\alpha_{L}=0,0.49$ and 0.64 . Table 2 summarises the results of the fire tests. The loading combinations applied in each of the tests is reported in terms of the parameters $\alpha_{K}$ and $\alpha_{L}$. The maximum force generated by the restrained axial expansion and the temperature at which the column fails are also reported. As initial curvatures can have a significant effect on the columns behaviour these values are also reported where possible. Figures 4-a and 4-b show the magnitudes of axial restraint force against temperature for the two restraint only tests reported in Table 2. Figures 4-c and d present the magnitude of both the applied load and restraint force with temperature for tests TP112 and TP116 both of which involve an applied load equivalent to $\alpha_{L}=0.64$ and restraint levels of $\alpha_{K}=0.042$ and 0.32 respectively.

TABLE 2 . High temperatures tests results of the pilot study.

\begin{tabular}{|c|c|c|c|c|l|}
\hline $\begin{array}{l}\text { Degree of } \\
\text { Restraint } \alpha_{\mathrm{K}}\end{array}$ & $\begin{array}{l}\text { Specimen } \\
\text { Reference }\end{array}$ & $\begin{array}{l}\text { Loading } \\
\text { Level } \alpha_{\mathrm{L}}\end{array}$ & $\begin{array}{l}\text { Max. Generated } \\
\text { Force }\end{array}(\mathbf{K N})$ & $\begin{array}{l}\text { Failure } \\
\text { Temperature (C) }\end{array}$ & $\begin{array}{l}\text { Initial } \\
\text { Curvature (mm) }\end{array}$ \\
\hline \multirow{2}{*}{0} & TP105 & 0.49 & 0 & 552 & --- \\
\hline \multirow{3}{*}{0.042} & TP102 & 0 & 36 & 518 & --- \\
\cline { 2 - 6 } & TP106 & 0.49 & 8 & 243 & 4.2 \\
\cline { 2 - 6 } & TP112 & 0.64 & 13 & 223 & 0.3 \\
\hline \multirow{3}{*}{0.32} & TP115 & 0 & 72 & 223 & 0.15 \\
\cline { 2 - 6 } & TP114 & 0.49 & 30 & 230 & 2.2 \\
\cline { 2 - 6 } & TP116 & 0.64 & 47 & 177 & 1.8 \\
\hline
\end{tabular}

By comparing Figures 4-a and 4-b it can be seen that in the case of high levels of relative stiffness $\alpha_{K}$, the failure temperature was significantly reduced as much higher loads were created at lower temperatures. In test TP102 (Figure 4-a) the failure is due to the effect of elevated temperatures on material properties which reduces the load capacity of the member where as test TP115 by contrast the restraint force generated in the column actually exceeds the ambient temperature load capacity when failure occurs thus the affect of elevated temperatures of material properties is not as significant in this test. It can be seen from comparison of the post buckling phases that where higher temperatures are present a more 


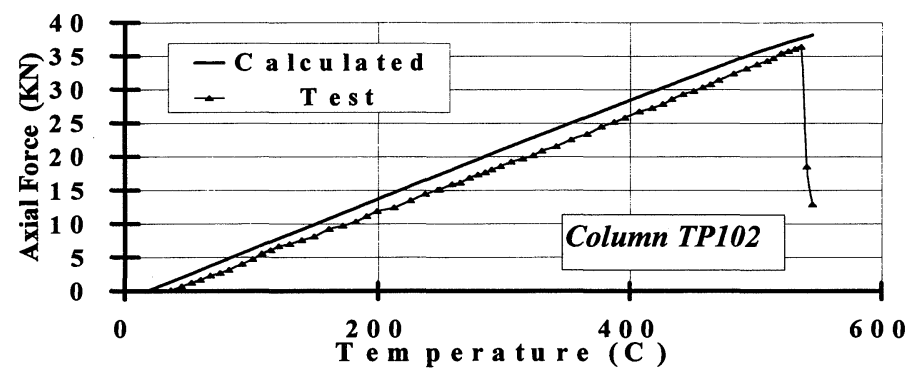

(a)

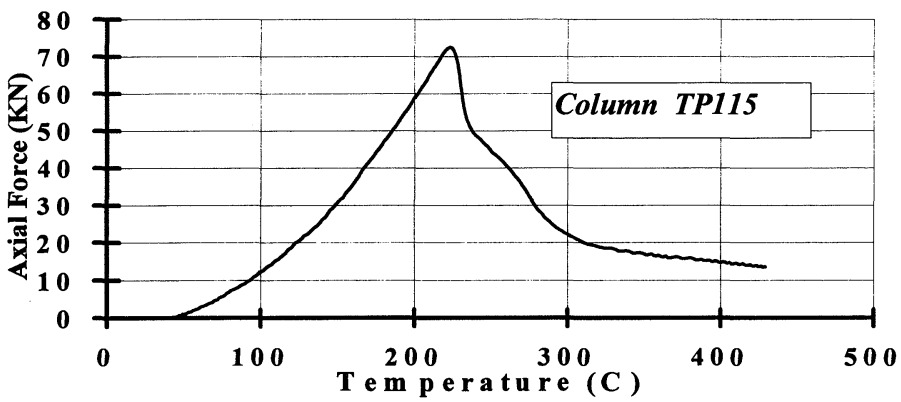

(b)

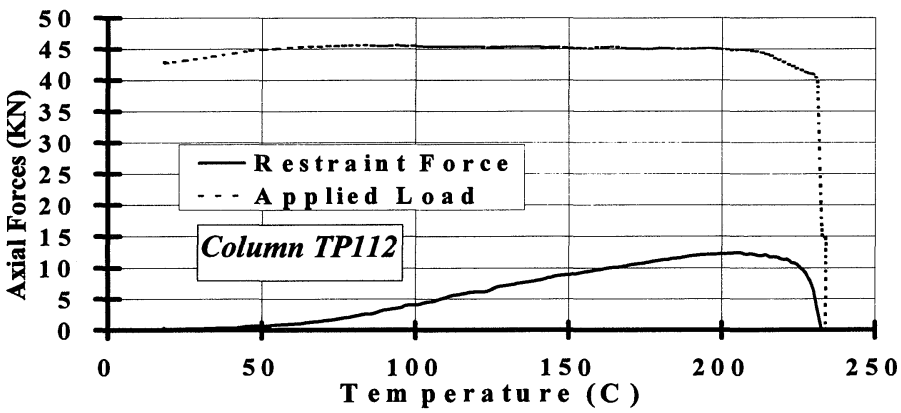

(c)

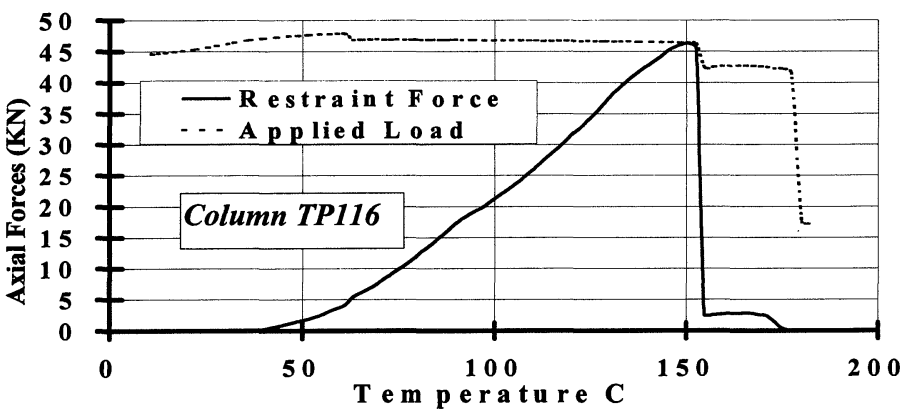

(d)

FIGURE 4. Axial forces generated during high temperature tests. 
rapid decrease in load occurs. Figure 4-c shows the axial force generated during test TP112. Comparing these results with tests TP102 it can be seen that the restraint force at any given temperature is reduced due to the axial deflection of the column, caused by the applied load. By comparing Figures 4-a , b with Figures 4-c, $d$ it can be observed that the introduction of an applied load reduces the fire resistance at all levels of applied loads.

Referring to the maximum force generated by axial restraint reported in Table 2 it can be seen that column TP106 has a lower maximum value of restraint force than test TP112 although the applied load is higher in the latter case. This is due to high value of initial curvatures occurring in TP106 which if combined with axial load serve to increase lateral deflection causing an end shortening effect which in turn will inhibit the generation of restraint forces. In addition the load capacity of the column will also be affected hence reducing the failure temperatures in comparison with straight column subjected to the same loading combinations. This observation can also be applied to tests TP114 and TP116.

The experimental values of axial restraint forces generated in column TP102 were compared with values calculated using equation (7) and the values obtained are shown in Figure 4-a along side the experimental results. It can be seen from Figure 4-a that the theoretical values of axial restraint force shows good agreement with the experimental data.

\section{CONCLUSIONS AND FURTHER RESEARCH}

1. The pilot study has provided commissioning of test apparatus and permitted the development of a testing methodology for columns in fire subjected both to applied load and restraint forces. Special outcomes were:

a) Imposing restraint against axial column expansion reduces the fire resistance of the steel columns.

b) For unloaded columns increasing the degree of restraint $\alpha_{K}$ from 0.04 to 0.32 almost doubled the value of the axial force generated in the column during heating and minimised the failure temperature from $518^{\circ} \mathrm{C}$ to $223^{\circ} \mathrm{C}$.

c) For columns loaded at 0.64 of its load capacity increasing the restraint level $\alpha_{K}$ from 0.04 to 0.32 increased the generated force by a factor of 3.5 and reduced the failure temperature from $223^{\circ} \mathrm{C}$ to $185^{\circ} \mathrm{C}$.

d) It is important in similar tests to consider imperfection as the pilot study showed that initial curvature and friction at the end supports minimised the load capacity of the columns by $\% 12.5$ in average in comparison with Euler formula calculations.

2. The major experimental study is now in progress and is scheduled for completion in March 1997. From this study an integral experimental database will be available to underpin the formulation of design guides. 


\section{REFERENCES}

1. Anderberg, Y., Forsen, N. E. and Aasen, B., "Measured And Predicted Behaviour Of Steel Beams And Columns In Fire", Fire Safety Science - Proceedings of the First International Symposium, 259-269, USA, 1985.

2. Bennetts, I. D., Goh, C. C., O'Meagher and Thomas I. R., "Restraint Of Compression Members In Fire", Report MRL/PS65/89/002, September, 1989.

3. Burgess, I. W. and Najjar, S. R., "A Simple Approach To The Behavior Of Steel Columns In Fire”, Journal of Constructional Steel Research, 31:1, 115-134, 1994.

4. Franssen, J. -M. and Dotreppe, J. C., "Fire Resistance Of Columns In Steel Frames", Fire Safety Journal, 19:2-3, 159-175, 1992.

5. Franssen, J. -M., Schleich, J. -B. and Gajot, L. -G., "Simple Model For The Fire Resistance Of Axially Loaded Members According To Eurocode 3", Journal of Constructional Steel Research, 35:1, 49-69, 1995.

6. Olawale, A. O. and Plank, R. J. "Collapse Analysis Of Steel Columns In Fire Using A Finite Stripe Method", International Journal for Numerical Methods In Engineering, 26:12, 2755-2764, 1988.

7. Sullivan, P. J. E, Terrro, M. J., and Morris, W. A., "Critical Review Of Fire Dedicated Thermal And Structural Computer Programs", Journal of Applied Fire Science, 3:2, 113-135, 1993/1994.

8. Draft for Eurocode 3, Part 1.2, August 1993.

9. Bailey, C. G., Wadee, M., Baltzer, K., and Newman, G. M., "The Behavior Of Steel Columns In Fire", Report RT524, Version 1, submitted by The Steel Construction Institute to the Department of Environment, UK, March, 1996.

10. "Investigation Of Broadgate Phase 8 Fire", Report of Fire Engineering Consultant Ltd., SCIF Fire Engineering Group, UK, June, 1991.

11. Franssen, J. -M., "Axially Restrained Columns Tests Database", Report of The University of Liege, Belgium, 1994, (Personnel communications).

12. Janss, J. and Minne, R., "Buckling Of Steel Columns In Fire Conditions", Fire Safety Journal, 4, 227-235, 1981/1982.

13. Witteveen, J., and Twilt, L., "A Critical View On The Results Of Standard Fire Resistance Tests On Steel Columns", Fire Safety Journal, 4, 259-270, 1981/1982.

14. Lennon, T., "Local Column Heating Fire", Cardington Conference, Building Research Establishment, UK, 1994.

15. Marshall, W. T. and Nelson, H., Structures, Longman Group, pp. 420-225, London, 1990.

16. British Standard Institution BS5950. "The Structural Use Of Steel Work In Building, Part1:Code Of Practice For Design In Simple And Continuos Construction", BSI, London, 1990. 